\title{
Application of a Modified Disk for Testing Orally Disintegrating Tablets by USP <701>
}

\author{
James Klancke*, Pam Payne, and Craig Nordholm
}

CIMA Labs Inc., Minneapolis, MN, USA

\section{ABSTRACT}

e-mail: jamesklancke@gmail.com

The USP $<701>$ basket-rack assembly with disks is applied to the disintegration testing of orally disintegrating tablets (ODTs). Although $<701>$ is generally suitable for testing ODTs as described, interference arising from the physical interaction of the tablet and disk is observed for many ODTs. Described herein is an innovative yet simple modification to the commercially available disk, developed to circumvent this interference and allow for testing a wider range of tablets. The 'footed disk' modification is practical in that it uses materials that are readily available, maintains correct density, and produces no interference during execution of the test procedure. These characteristics support a favorable status for the application of a modified disk for testing ODTs in individual regulatory filings.

KEYWORDS: disintegration, tablets, orally disintegrating, USP $<701>$

\section{INTRODUCTION}

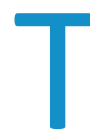

he U.S. Food and Drug Administration (FDA) guidance recommends the use of the USP $<701>$ basketrack apparatus for testing orally disintegrating tablets (ODTs) (1). The disintegration apparatus is consistently and widely utilized, as the general chapter $<701>$ is harmonized with the European, Japanese, and international pharmacopeias. Disintegration is an important test, because it is used as a measure of product performance at release and throughout shelflife. For some ODTs, disintegration may even be used in quality control as an alternate to a formal dissolution test. Alternative tests have been proposed that do not utilize the compendial apparatus $(2,3)$.

USP $<701>$ describes the disintegration test for solid oral dosage units and is used to determine whether disintegration occurs within the prescribed time. When specified in the monograph, cylindrical disks (discs) are employed to aid in the testing of solid dosage forms such as ODTs that tend to float in the immersion media (usually water). The disks help to ensure submersion of the dosage unit and the necessary surface wetting to facilitate disintegration. Disks that contain an embedded conductor are also a necessary component for automated endpoint detection for an apparatus with such capability. A detailed description of the dimensions, materials, and features of the disks are given in $<701>$.
The USP apparatus and test conditions were designed long before rapidly disintegrating dosage forms became more commonplace in the last 20 years. Undoubtedly, it was anticipated that even with the agitation provided by the reciprocating motion of the apparatus, the test would run for several minutes for solid dosage forms and perhaps up to several hours (note: general limit of 4 hours for buccal tablets in $<701>$ ). The FDA guidance for ODTs describes expectations of fast disintegration times typically on the order of not more than (NMT) 30 seconds, although the European guidance is NMT 3 minutes. On time scales of less than 30 seconds or even up to 60 seconds, certain types of interference may be observed that often go unnoticed for dosage units such as plaincoated or uncoated tablets that require many minutes to disintegrate. For example, certain ODT formulations are observed to adhere to the underside of the disk during the test, preventing effective wetting of the tablet and artificially extending the reported disintegration time by up to 10 or 20 seconds. ODT formulations often contain a significant proportion of active ingredient particles that are taste-masked with polymeric coatings. As the tablet disintegrates, these coatings may become sticky upon wetting. Additionally, ODT formulations typically contain other excipients designed to provide a pleasing, creamy texture, which, in turn, tends to be a soft, partially hydrated mass during disintegration. The interfering effect of the combination of sticky polymeric coatings and soft masses is exacerbated when testing larger ODTs,

* Corresponding author. 
especially those above $500 \mathrm{mg}$ that carry a higher drug load. Alternatively, conventional solid oral dosage forms may disintegrate into somewhat coarse granules that dissipate readily during the agitation part of the test. Excluding the disk from the testing parameters for an ODT is undesirable, as the tablets typically have low density and tend to float in the immersion media. Other options, such as placing the tablet into a sinker or securing it to the bottom of the disintegration tube to prevent flotation, would not be allowed (4).

An innovative disk modification has been developed to prevent adherence of the partially disintegrated tablets to the underside of the disk. The modification is practical in that it uses materials that are readily available, maintains correct density, and produces no interference with execution of the test procedure or the results. These characteristics support favorable status for the application of a modified disk for testing ODTs in individual regulatory filings.

\section{MATERIALS AND METHODS}

\section{Disk Modification and Assembly}

Prior to any physical modification of the disk, attempts were made to minimize the interaction of the tablet face with the disk by orienting the disk perpendicularly (vertically on edge within the disintegration tube) to the tablet face. Vertical orientation resulted in poor performance, as roughly half of the tablets being tested slipped up alongside the vertically oriented disk and floated to the surface of the test fluid. Furthermore, the disks would not readily move up and down in tubes during the cycling of the apparatus.

Several disk modification concepts with different materials and dimensions were evaluated prior to reaching a suitable design. These concepts focused on maintaining a small separation between the tablet and the disk by inserting or affixing short posts or 'feet' to the underside of the disk. Various materials were evaluated for the feet, including wire, pins, and common laboratory tubing. These modifications were challenging to fabricate, lacked robustness, and strayed from the desired specific gravity.

Ultimately, the commercially available USP disks were modified to include four $1 / 8$-in. long $\times 1 / 8$-in. diameter acrylic posts (serving as feet) inserted into the underside of the disk as shown in Figure 1A. Commercially available clear acrylic rod with $1 / 8$-in. nominal diameter has a tolerance of NMT 0.005 in. and a density of approximately $1.2 \mathrm{~g} /$ $\mathrm{cm}^{3}$ (McMaster-Carr PN 8531K11). As shown in Figure
$1 \mathrm{~B}$, four holes are drilled along the inner outlined circle of the disk to allow insertion of the posts, which are then mechanically trimmed or ground down to length with an abrasive so that $1 / 8$ in. protrudes from the face of the disk. The five holes and the four trapezoid-shaped planes present on the unmodified disk are not impacted by the modification. Through experimentation, a disk with four $1 / 8$-in. posts was found to be optimum and robust in testing.

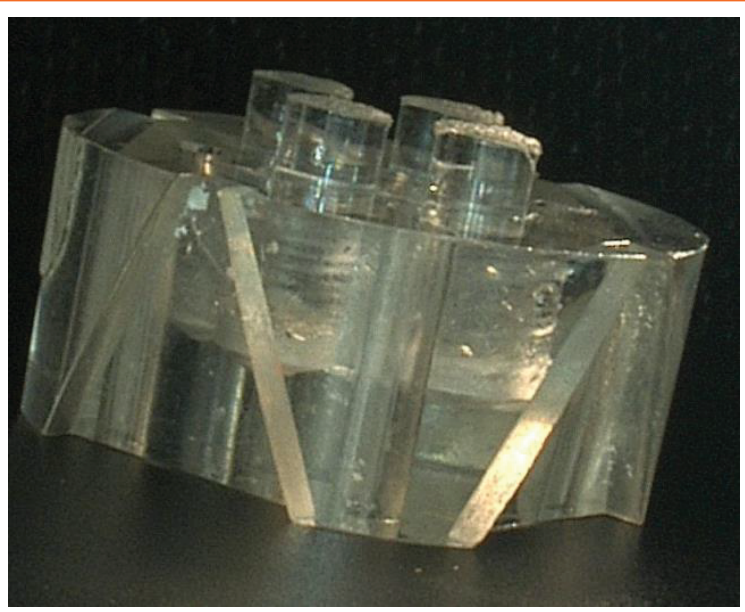

Figure $1 A$. Side view of modified disk.

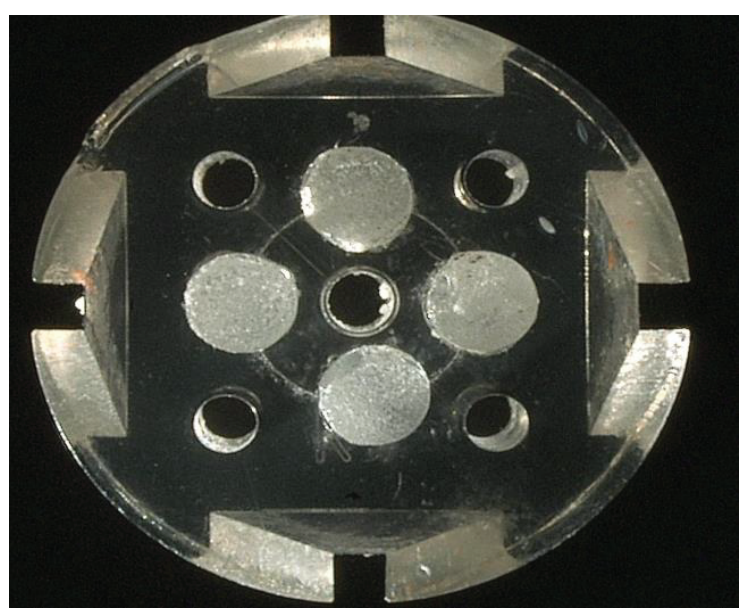

Figure 1B. Bottom view of modified disk.

The assembly procedure is as follows. Mark the four holes (evenly spaced) to be drilled with a punch point on the inner outlined circle on the underside of the disk. Using a \#30 or 0.1285 -in. drill bit, drill holes to a depth of $1 / 4$ in. Cut the acrylic rod into four $3 / 8$-in. posts. Apply a small amount of cyanoacrylate-type glue on the end of each post and press them into the drilled holes in the disk using an arbor press. Sand the posts evenly to a height of $1 / 8$ in. above the disk surface to complete the assembly. 


\section{RESULTS AND DISCUSSION \\ Performance of Modified Disks}

Trials with the modified disks were successful in that artificially long disintegration times were not observed for several formulations that contain excipient or polymeric particles, which become sticky during the disintegration process. The $1 / 8$-in. posts on the modified disk afford continuous separation of the underside of the disk from the dosage unit during the test and allow the immersion fluid to reach the surface of the tablet. Without the posts and physical separation they provide, the dosage unit could otherwise come in contact with the disk and interfere with the disintegration process. Even larger ODTs with diameters of $5 / 8$ in. and masses on the order of 1 gram were readily tested without interference when using the modified disks. Additionally, the modified disks do not accelerate the disintegration of the tablets during testing.

Ten drug products labeled as ODTs were evaluated in deionized water using an Erweka ZT72 USP disintegration apparatus (Erweka GmbH, Heusenstamm, Germany). Table 1 shows the performance of the modified disk for various ODTs. Disintegration endpoints were determined electronically, with visual confirmation, when using the conventional disks. Disintegration endpoints were determined visually when using the modified disks. For ODTs with disintegration times of NMT 30 seconds, up to an extra 20 seconds is required to achieve tablet disintegration when using the conventional disk because of sticking when compared to the modified disk. The interference is appreciable in most cases relative to a 30-second limit. It should be noted that certain products may have approved product specifications of more than 30 seconds. While Orapred and the relatively large Remeron tablets showed minor sticking as indicated, both products generally moved freely within the disintegration tubes during the test. Table 2 shows several products that did not stick to the underside of the conventional disk. Zydis products were not included in the test survey, with reported disintegration times of less than four seconds for several products (5).

The modified disk could also be beneficial when applied to solid oral dosage forms aside from ODTs. Chewable tablets, for example, may also contain tastemasked polymer-coated drug particles that, along with extragranular excipients, could produce a sticky mass during disintegration.
Table 1. Performance of Modified Disk: Products that Stick to the Conventional Disk

\begin{tabular}{|c|c|c|c|c|}
\hline \multirow{2}{*}{$\begin{array}{l}\text { Orally } \\
\text { Disintegrating } \\
\text { Product }\end{array}$} & \multirow{2}{*}{$\begin{array}{l}\text { Diameter, } \\
\text { Shape, and } \\
\text { Mass }\end{array}$} & \multicolumn{2}{|c|}{$\begin{array}{c}\text { Approximate } \\
\text { Disintegration Time in } \\
\text { Deionized Water (s) }\end{array}$} & \multirow{2}{*}{$\begin{array}{l}\text { Approximate } \\
\text { Disk } \\
\text { Interference } \\
\text { Time (s) }\end{array}$} \\
\hline & & $\begin{array}{l}\text { USP } \\
\text { Disk }\end{array}$ & Modified Disk & \\
\hline $\begin{array}{l}\text { Fazaclo ODT, } \\
200 \mathrm{mg}\end{array}$ & $\begin{array}{l}5 / 8 \text { in., flat- } \\
\text { face, } \\
1360 \mathrm{mg}\end{array}$ & 45 & 25 & 20 \\
\hline $\begin{array}{l}\text { Orapred ODT, } \\
\quad 30 \mathrm{mg}\end{array}$ & $\begin{array}{l}1 / 2 \text { in., flat- } \\
\text { face, } \\
570 \mathrm{mg}\end{array}$ & 27 & $\begin{array}{l}20 \text { (minor } \\
\text { momentary } \\
\text { sticking) }\end{array}$ & 7 \\
\hline $\begin{array}{c}\text { Remeron } \\
\text { SolTabs, } \\
45 \mathrm{mg}\end{array}$ & $\begin{array}{l}5 / 8 \text { in., flat- } \\
\text { face, } \\
930 \mathrm{mg}\end{array}$ & 30 & $\begin{array}{c}20 \\
\text { (minor sticking } \\
\text { during last } 10 \mathrm{~s} \text { ) }\end{array}$ & 10 \\
\hline $\begin{array}{c}\text { Unisom } \\
\text { Sleepmelts }\end{array}$ & $\begin{array}{l}1 / 2 \text { in., flat- } \\
\text { face, } \\
640 \mathrm{mg}\end{array}$ & 25 & 18 & 7 \\
\hline Alavert ODT & $\begin{array}{l}3 / 8 \text { in., flat- } \\
\text { face, } \\
300 \mathrm{mg}\end{array}$ & 15 & 12 & 3 \\
\hline $\begin{array}{c}\text { Zyrtec } \\
\text { Dissolve Tabs }\end{array}$ & $\begin{array}{l}3 / 8 \text { in., flat- } \\
\text { face, } \\
325 \mathrm{mg}\end{array}$ & 15 & 15 & none \\
\hline $\begin{array}{l}\text { Children's } \\
\text { Allegra } \\
\text { ODT }\end{array}$ & $\begin{array}{l}7 / 16 \text { in., flat- } \\
\text { face, } \\
460 \mathrm{mg}\end{array}$ & 20 & 11 & 9 \\
\hline
\end{tabular}

Insoluble excipients present in Table 1 products: ethylcellulose, hydroxypropyl cellulose, microcrystalline cellulose, polyvinylpyrolidone (crospovidone), methacrylic acid copolymer, povidone. $O D T$, orally disintegrating tablet.

Table 2. Products that Do Not Stick to the Conventional Disk

\begin{tabular}{|c|c|c|}
\hline \multirow[t]{2}{*}{$\begin{array}{l}\text { Orally Disintegrating } \\
\text { Product }\end{array}$} & \multirow[t]{2}{*}{$\begin{array}{c}\text { Diameter, Shape, and } \\
\text { Mass }\end{array}$} & $\begin{array}{l}\text { Approximate } \\
\text { Disintegration } \\
\text { Time in } \\
\text { Deionized } \\
\text { Water (s) }\end{array}$ \\
\hline & & USP Disk \\
\hline $\begin{array}{l}\text { CVS Health Children's } \\
\text { Allergy Relief Rapid } \\
\text { Melt, grape flavor }\end{array}$ & $\begin{array}{l}1 / 2 \text { in., flat-face (very } \\
\text { slightly biconvex), } \\
600 \mathrm{mg}\end{array}$ & 250 \\
\hline $\begin{array}{l}\text { CVS Health Children's } \\
\text { Allergy Relief Rapid } \\
\text { Melt, bubble gum flavor }\end{array}$ & $\begin{array}{c}1 / 2 \text { in., flat-face, } \\
580 \mathrm{mg}\end{array}$ & 225 \\
\hline $\begin{array}{l}\text { Equaline Jr. Strength } \\
\text { Acetaminophen, } 160 \\
\mathrm{mg} \text {, grape rapid tabs }\end{array}$ & $\begin{array}{l}5 / 8 \text { in., flat-face on } \\
\text { one side, other side } \\
\text { has shallow center } \\
\text { depression with partial } \\
\text { bisect, } 1320 \mathrm{mg}\end{array}$ & 25 \\
\hline
\end{tabular}

Insoluble excipients present in Table 2 products: ethylcellulose polymers, polyethylene and polypropylene polymers, ethylcellulose, hydroxypropyl cellulose, polyethylene, and crospovidone. 


\section{CONCLUSION}

The modified disks allow determination of disintegration times for ODTs without interference, retain the use of the harmonized, compendial test apparatus, and are easy to fabricate.

\section{CONFLICT OF INTEREST}

The authors disclosed no conflicts of interest related to this study.

\section{REFERENCES}

1. Guidance for Industry: Orally Disintegrating Tablets. U.S. Department of Health and Human Services, Food and Drug Administration, Center for Drug Evaluation and Research (CDER), U.S. Government Printing Office: Washington, DC, 2008.

2. Park, J. H.; Holman, K. M.; Bish, G. A.; Krieger, D. G.; Ramlose, D. S.; Herman, C. J.; Wu, S. H. An alternative to the USP disintegration test for orally disintegrating tablets. Pharm. Tech., 2008, 32. Published August 2, 2008. Accessed April 4, 2018. http://www. pharmtech.com/alternative-usp-disintegration-test-orallydisintegrating-tablets?id=\&sk=\&date=\&pagelD=5.

3. El-Arini, S. K.; Clas, S-D. Evaluation of disintegration testing of different fast dissolving tablets using the texture analyzer. Pharm. Dev. Technol., 2002, 7, 361-371. DOI: 10.1081/PDT-120005732.

4. Brown, W., Marques, M. Question and answer section. Dissolution Technol., 2012, 19 (3), 44-45. DOI: 10.14227/ DT190312P43.

5. McLaughlin, R.; Banbury, S.; Crowley, K. Orally disintegrating tablets - the effect of recent FDA guidance on ODT technologies and applications. Pharm. Tech., 2009, 2009 Supplement. Published September 1, 2009. Accessed April 4, 2018. http:// www.pharmtech.com/orally-disintegrating-tablets-effectrecent-fda-guidance-odt-technologies-and-applications?id=\&sk $=\&$ date $=\&$ page $I D=6$. 